\title{
Oxidation of Cyclohexane by Transition Metal Oxides on Zeolites
}

\author{
Christopher R. Riley, Nancy E. Montgomery, Nada N. Megally, Jessica A. Gunn and \\ L. Shannon Davis ${ }^{*}$
}

Department of Chemistry, 250 Forest Drive, Georgia Southern University, Statesboro, GA 30460, USA

\begin{abstract}
Transition metals ( $\mathrm{Co}, \mathrm{Mn}, \mathrm{Fe}$, and $\mathrm{Cu}$ ) were deposited as the hydrated oxides on a series of zeolites $(\mathrm{Y}, \beta$, ZSM-5, mordenite, and ferrierite) and examined for activity for the oxidation of cyclohexane at $70^{\circ} \mathrm{C}$ and ambient pressure. The materials that demonstrated catalytic activity under these extremely mild conditions were the cobalt-based catalysts. The copper and copper/iron materials demonstrated stoichiometric activity for the oxidation of cyclohexane to cyclohexanol and cyclohexanone. The cobalt-based catalysts produced the intriguing products caprolactone, 1-hexanol, and 3-methyl-1-pentanol, as well as the expected cyclohexanol and cyclohexanone. Of most interest was the production of 1-hexanol, indicative of novel activity in the oxidative ring cleavage and oxidation of cyclohexane.
\end{abstract}

Keywords: Cyclohexane oxidation, cobalt, manganese, iron, copper.

\section{INTRODUCTION}

One of the principle aims of catalysis chemistry in the $21^{\text {st }}$ Century is the selective catalytic oxidation of alkanes [ 1 , 2]. One of the most industrially important oxidations of alkanes is the production of the cyclohexanone-cyclohexanol mixture known as KA oil from the air oxidation of cyclohexane. The commercially-practiced process suffers from low yields, low selectivities, and low conversions, as well as production of greenhouse gases and large quantities of waste. Cobalt and manganese salts have commonly been employed as catalysts for this reaction; however, the high activation energy of the $\mathrm{C}-\mathrm{H}$ bonds in cyclohexane dictates the use of high temperatures and subsequently high pressures to carry out this reaction commercially. Catalysts that enable the oxidation of cyclohexane under mild conditions (temperatures below the boiling point of cyclohexane) would alleviate this potential hazard as well as allow for more selective control of the reaction [3].

The use of zeolites in many forms has been explored for this reaction in hopes of advantageously directing the reaction through the use of the inherent pore structure of the materials or by incorporating catalysts inside those pores [4]. The so-called "ship-in-a-bottle" approach was widely explored but seldom applied to the oxidation of cyclohexane, or to the use of air as the oxidant; these prior studies used primarily tert-butyl hydroperoxide (TBHP) or similar oxidants as well as solvents [5-8]. Multiple studies of porphyrin or other macrocyclic ligand based transition metal complexes enmeshed in a zeolite cage, inorganic mimics of the naturally occurring cytochrome $\mathrm{P} 450$ enzyme, have also focused on the use of $\mathrm{H}_{2} \mathrm{O}_{2}$ or TBHP as oxidants for a wide variety of oxidations, including that of cyclohexane [9]. We report the results of a broad study of heterogeneous zeolite-

*Address correspondence to this author at the Department of Chemistry, 250 Forest Drive, Georgia Southern University, Statesboro, GA 30460, USA; Tel: (912) 478-5055; Fax: (912) 478-0699;

E-mail: sdavis@georgiasouthern.edu based catalysts for the oxidation of cyclohexane under mild conditions with unexpected results. Cobalt and manganese were chosen due to their prevalent use in many oxidations, including that of cyclohexane commercially. Copper was chosen for this study due to its activity in enzymatic oxidative transformations; iron was chosen due to its long history of selective oxidation and Fenton chemistry.

\section{MATERIALS AND METHODOLOGY}

\section{Chemicals and Reagents}

$\mathrm{CuSO}_{4} \cdot 5 \mathrm{H}_{2} \mathrm{O}, \quad \mathrm{FeCl}_{3} \cdot 6 \mathrm{H}_{2} \mathrm{O}, \quad \mathrm{CoCl}_{2} \cdot 6 \mathrm{H}_{2} \mathrm{O}, \quad \mathrm{MnSO}_{4}$, reagent grade cyclohexane, and $30 \% \mathrm{H}_{2} \mathrm{O}_{2}$ were obtained from Fisher Scientific. $\mathrm{H}^{+} \mathrm{Y}$ (Lot No. 2200-10), $\mathrm{H}^{+}$ Mordenite (Lot No. 2200-22), $\mathrm{NH}_{4}^{+}$Ferrierite (Lot No. 2200-38), $\mathrm{H}^{+}$ZSM-5(Lot No. 2200-50), and $\mathrm{H}^{+} \beta$ (Lot No. 2200-34) were purchased from Zeolyst International and used as received. Silica gel $(70-270$ Mesh, 60 ̊) was obtained from Aldrich Chemical. Deionized water $\left(\mathrm{dH}_{2} \mathrm{O}\right)$ was used as generated from a Barnstead Millipore 4-stage ion exchange unit at $18.3 \mathrm{M} \Omega$.

\section{Catalyst Preparation and Characterization}

A modification of a procedure for the preparation of an iron oxide zeolite catalyst active in phenol oxidation was used for the synthesis of all materials [10]. The metal oxides were prepared by simply dissolving $5.0 \mathrm{~g}$ of the chosen metal salt $\left(\mathrm{CuSO}_{4} \cdot 5 \mathrm{H}_{2} \mathrm{O}, \quad \mathrm{FeCl}_{3} \cdot 6 \mathrm{H}_{2} \mathrm{O}, \quad \mathrm{CoCl}_{2} \bullet 6 \mathrm{H}_{2} \mathrm{O}\right.$, $\mathrm{MnSO}_{4}$ ) in $50 \mathrm{~mL}$ of $\mathrm{dH}_{2} \mathrm{O}$ with stirring, adding $3.0 \mathrm{M} \mathrm{NaOH}$ dropwise until a $\mathrm{pH}$ of 10 was reached, and stirring the subsequent mixture for 30-45 minutes. The solids were separated by vacuum filtration, washed once with $\mathrm{dH}_{2} \mathrm{O}$, and dried in a $135^{\circ} \mathrm{C}$ oven. Mixed metal oxides were prepared similarly using a $50 / 50 \%$ by weight mixture of $\mathrm{CoCl}_{2} \cdot 6 \mathrm{H}_{2} \mathrm{O}$ and $\mathrm{MnSO}_{4}$ or a $60 / 40 \%$ by weight mixture of $\mathrm{CuSO}_{4} \cdot 5 \mathrm{H}_{2} \mathrm{O}$ and $\mathrm{FeCl}_{3} \cdot 6 \mathrm{H}_{2} \mathrm{O}$.

Preparation of the metal oxides on the zeolites followed a similar procedure using incipient wetness techniques. The metal salt or combination of salts totaling $5.0 \mathrm{~g}$ was first dissolved in $\mathrm{dH}_{2} \mathrm{O}$ with agitation, $5.0 \mathrm{~g}$ of powdered zeolite 
was added and suspended in solution, and $3.0 \mathrm{M} \mathrm{NaOH}$ was added dropwise until a $\mathrm{pH}$ of 10 was achieved. The mixture was stirred for 40 minutes and the solids vacuum filtered, washed, and dried overnight at $135^{\circ} \mathrm{C}$. The resulting solids were stored in a desiccator until required for use. Metal oxides on silica gel were produced by substituting silica gel for the zeolites in the preparation.

To prepare the minimum-cobalt catalysts, the procedure was modified slightly. The cobalt salt was dissolved in $\mathrm{dH}_{2} \mathrm{O}$ and the powdered zeolite was added to this solution with stirring. The mixture was stirred for 1 hour, then vacuum filtered. The resultant solids were slurried in $50 \mathrm{~mL}$ of $\mathrm{dH}_{2} \mathrm{O}$, and the $\mathrm{pH}$ of this solution raised to 10 . The remainder of the procedure was followed as outlined above.

In total, a family of seven catalysts - metal oxides, oxides on silica gel, and oxides on five different zeolites was prepared for each metal or combination of metals. Samples were characterized before and after oxidation reactions using a Nicolet Nexus 470 FT-IR with ATR and DRIFT stage attachments. Metals analysis in the liquid phase was carried out using UV-visible spectroscopy with a Shimadzu UV-2401-PC instrument or a Perkin Elmer NexION 300 ICPMS with internal standard.

\section{Catalytic Reactions and Product Analysis}

Oxidation reactions were carried out in three-neck Pyrex round bottom flasks equipped with a reflux condenser and a Teflon coated magnetic stirbar. Fisher Scientific grade cyclohexane (100 mL) and 3 mmoles (on a metals basis) of prepared catalyst were heated to $70^{\circ} \mathrm{C}$ using an electric heating mantle and variable temperature controller. A steady stream of medical grade air was bubbled into the solution using a needle valve for air rate control and a 12" stainless steel 18 gauge needle injector. Hydrogen peroxide was added to the solution to initiate the reaction. The reaction was allowed to run for 48 hours, with samples taken at 0,24 , and 48 hours. Each oxidation was repeated a minimum of three times due to well known issues in the reproducibility of cyclohexane oxidations. After the reaction was complete, used catalyst was dried for a 24 hour period in air at room temperature and retained for analysis.

Liquid product analysis was performed with a Shimadzu GC-17A FID equipped with a Restek-200 $0.53 \mathrm{~mm} \times 15 \mathrm{~m}$ capillary column or a Shimadzu GCMS - QP5000 equipped with a Restek-200 $0.25 \mathrm{~mm}$ x 30m capillary column. The GC conditions were a programmed temperature ramp $\left(70-190^{\circ} \mathrm{C}\right.$ at $10^{\circ} \mathrm{C} / \mathrm{min}$ ) with a split ratio of $20: 1$, and a total flow of 70 $\mathrm{mL} / \mathrm{min}$; GC conditions for the GCMS were a programmed temperature ramp $\left(70-190^{\circ} \mathrm{C}\right)$ with a split ratio of $150: 1$, and a total flow of $77 \mathrm{~mL} / \mathrm{min}$; the MS was performed using electron impact. Calibration curves using either external standards or standard addition methods were used to quantify product production. Products identified as "trace" could be identified but not quantified as the amounts were below the LOQ for the methods employed.

\section{RESULTS AND DISCUSSION}

Catalyst synthesis was carried out under conditions that quantitatively deposited the metals onto the zeolite. The quantity of metals remaining in the filtrate after the deposition step was determined by UV-visible spectroscopy; in all cases no metals were detected spectroscopically in the filtrate. As the $\mathrm{pH}$ increased above 10.0, the percent yield typically decreased, due to the formation of soluble metalhydroxide complexes; this yield loss was particularly pronounced in the $\mathrm{Cu} / \mathrm{Fe}$ mixed metal synthesis. For this reason, the $\mathrm{pH}$ was maintained at 10 for the synthesis procedure. For the minimum cobalt materials, ICPMS analysis of the solutions prepared by dissolving the zeolite in concentrated acid revealed that $0.30 \%(\mathrm{w} / \mathrm{w})$ of the available cobalt was ion-exchanged into the zeolite.

Blank oxidation experiments consisting of combinations of substrate, air, and hydrogen peroxide were carried out for both the metal and mixed metal materials. Multiple replicates of these blanks demonstrated that in all cases, products were only formed when all four components (the zeolite catalyst, air, substrate, and hydrogen peroxide) were added; without all of these variables present no reaction occurred.

The oxidation of cyclohexane was carried out under pseudo-first order conditions and with no auxiliary solvent. The amount of $\mathrm{H}_{2} \mathrm{O}_{2}$ added was sufficiently small (100:1 molar ratio of metal to peroxide) as to not require the use of phase transfer reagents and acted as the reaction initiator; the primary oxidant in these experiments was $\mathrm{O}_{2}$. In all cases, the conversion of cyclohexane was low $(0.3 \%)$ and the production of products was small. Table 1 identifies the results from triplicate oxidation experiments.

In the case of the zeolite-supported cobalt oxides with the maximum amount of cobalt present, several surprising results were obtained. The oxides on ZSM-5 produced trace quantities of two products that were unidentifiable by GCMS. Two of the family actively generated quantifiable products and both were $100 \%$ selective - the oxides on silica gel and the ferrierite. In the case of the silica gel materials, the product was identified by GCMS as caprolactone. The Baeyer-Villiger reaction of cyclohexanone to produce caprolactone, particularly in the presence of Lewis acids, is a well known reaction and is the most likely mechanism for the formation of this product from the oxides supported on silica gel $[11,12]$. The ferrierite material produced the interesting product 3-methyl-1-pentanol, indicating the cleavage of the cyclohexane ring and subsequent oxidation of one of the carbons. Turnover numbers, calculated simply as mole product produced/mole cobalt, were small $(<50)$, as expected as is the conversion $(0.3 \%)$ on a molar basis. A radical mechanism explains the isomerization to a pendant methyl group as well as the oxidation of only one of the ringcleaved carbon atoms. However, $100 \%$ selectivity is not commonly observed with free radical based reactions. In any event, the cleavage of the cyclohexane ring, with subsequent oxidation to produce the alcohols, is an exciting result at these mild temperatures and pressures. No spectroscopic differences in either of these catalysts before or after the reaction were observed. A possible set of pathways for the production of the products observed in the cobalt-zeolite catalyzed reactions is shown in Scheme $\mathbf{1}$ below. This Scheme invokes a classical free radical autoxidation type mechanism with a key intermediate of the radical hydroperoxide ROO. The decomposition of this material, which can happen through several different mechanisms, explains the wide range of products observed in these 
Table 1. Products from the Oxidation of Cyclohexane at $70^{\circ} \mathrm{C}$ and at $0.3 \%$ Conversion

\begin{tabular}{|c|c|c|c|c|c|c|}
\hline Catalyst & $\mathrm{Co}_{(\max )}$ & $\mathbf{C o}{ }_{(\min )}$ & Mn & Co/Mn & $\mathrm{Cu}$ & $\mathrm{Cu} / \mathrm{Fe}$ \\
\hline Metal Oxides & NR & NR & NR & NR & NR & NR \\
\hline $\mathrm{SiO}_{2}$ & $\begin{array}{c}\text { Cap } \\
(100 \%)\end{array}$ & $\begin{array}{c}\text { 3-MP } \\
(100 \%)\end{array}$ & NR & $\mathbf{A}+\mathbf{K}^{*}$ & NR & $\mathbf{A}+\mathbf{K}^{*}$ \\
\hline $\mathbf{H}^{+} \mathbf{Y}$ & NR & NR & NR & $\mathbf{A}+\mathbf{K}^{*}$ & $\begin{array}{c}\mathrm{A}+\mathrm{K} \\
(\mathbf{5 0} \% \mathrm{~A}, \mathbf{5 0} \% \mathbf{K})\end{array}$ & $\mathbf{A}+\mathbf{K}$ \\
\hline $\mathbf{H}^{+} \boldsymbol{\beta}$ & NR & $\begin{array}{c}1-\text { Hex } \\
(100 \%)\end{array}$ & NR & $\mathbf{A}+\mathbf{K}^{*}$ & Unk $^{*}$ & NR \\
\hline $\mathbf{H}^{+}$ZSM-5 & Unk $^{*}$ & $\begin{array}{c}K \\
(100 \%)\end{array}$ & NR & NR & $\mathrm{K}^{*}$ & $\mathbf{K}^{*}$ \\
\hline $\mathbf{H}^{+}$Mordenite & NR & $\begin{array}{c}3-\mathrm{MP} \\
(100 \%)\end{array}$ & NR & Unk $^{*}$ & NR & $\begin{array}{c}\mathbf{A}+\mathbf{K} \\
(\mathbf{5 0 \%} \mathbf{A}, \mathbf{5 0 \%} \\
\mathbf{K})\end{array}$ \\
\hline $\mathbf{N H}_{4}{ }^{+}$Ferrierite & $\begin{array}{c}\text { 3-MP } \\
(100 \%)\end{array}$ & $\begin{array}{c}\text { 3-MP } \\
(100 \%)\end{array}$ & NR & NR & Unk $^{*}$ & $\begin{array}{c}\mathbf{A}+\mathbf{K} \\
(\mathbf{5 0 \%} \mathbf{A}, \mathbf{5 0 \%} \\
\mathbf{K})\end{array}$ \\
\hline
\end{tabular}

Table Abbreviations:

$\mathrm{NR}=$ no reaction

$\mathrm{A}=$ cyclohexanol (identified in the scheme as $\mathbf{1}$ ).

$\mathrm{K}=$ cyclohexanone (identified in the scheme as $\mathbf{2}$ ).

Cap $=$ Caprolactone $($ (identified in the scheme as $\mathbf{3})$.

1 -Hex $=$ (identified in the scheme as 4).

3-MP = 3-methyl-1-pentanol (identified in the scheme as 5).

Unk $=$ unidentified products.

Table Notes:

${ }^{*}$ Trace products identified by retention time but below the LOQ for the analytical method used.

$\%$ Selectivity for quantified products are given in ().

reactions. The only plausible explanation for the high selectivity observed is that the low conversion of cyclohexane allowed for fewer intrarmolecular interactions with other radical species in solution, thus limiting the number of potential products produced.

As prepared, the cobalt oxides in the maximum case would be expected to cover the surface of the supports completely, and while incorporated into the pores of the zeolite, the blanket coverage would inhibit any penetration of substrate into the holes. Another family of cobalt catalysts using the minimum amount of cobalt was prepared for comparison to the maximum cobalt catalysts. The time needed for the maximum ion exchange of cobalt in the zeolite was determined to be 30 minutes by UV-visible spectroscopy of the filtrate. These catalysts, interestingly, gave entirely different results in the oxidation of cyclohexane, implying that the chemistry involved is both a function of the support and its structure as well as the amount of metal on the supports. The minimum cobalt materials which were active in this oxidation were the silica

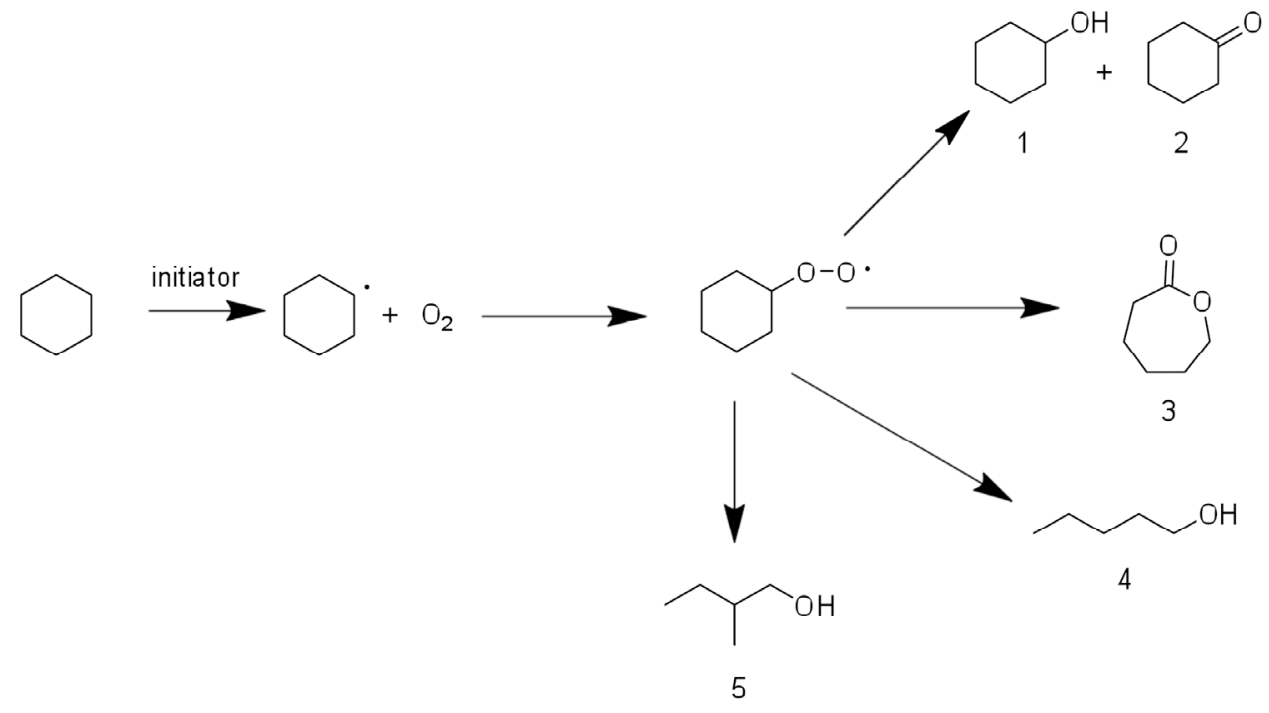

Scheme 1. Cobalt-zeolite catalyzed reaction pathways. 
gel and the $\beta$, ZSM-5, mordenite, and ferrierite zeolites. In all cases for this set of catalysts, the reaction was found to be stoichiometric. The amount of product quantified was produced in a 1:1 molar ratio to the amount of cobalt present in the zeolite. Again, no spectroscopic difference in the catalysts before and after the reaction was observed. The same 3-methyl-1-pentanol product observed in the maximum cobalt case was produced by three of the catalysts (silica, mordenite, and ferrierite). Only cyclohexanone was produced by the ZSM-5 material. The most interesting result from all of these experiments was the production of 1hexanol by the $\beta$ zeolite; this product is interesting as it indicates ring cleavage, again remarkable at these mild temperatures. While these results do not distinguish decisively between the role of the zeolite and the metal oxide involved, the difference in activity of these catalysts under such mild conditions is intriguing. Further study to determine the mechanism involved and to further explore the potential of a one step oxidation of cyclohexane to adipic acid with these materials is underway.

The entire family of manganese catalysts was inactive in this reaction under these conditions. Given that manganese salts are commonly used as yield enhancers in the commercial, cobalt-catalyzed oxidation of cyclohexane, this result is quite unusual [3]. A blended metal catalyst of equimolar amounts of cobalt and manganese showed slight activity for the oxidation. Trace quantities of the expected products, cyclohexanol and cyclohexanone, were produced by the silica gel and the $Y$ and $\beta$ zeolites. The mordenite material also produced trace quantities of products that were unable to be identified using GCMS or GC-FID. The relative inactivity of the blended materials is due to the apparent inhibitory presence of the manganese in these systems.

In the copper family of catalysts, four of the zeolite supported materials (ferrierite, $\beta$, ZSM-5, and Y) produced products in this oxidation. The most active catalyst was the zeolite Y, generating the most products - the expected products cyclohexanol and cyclohexanone and trace amounts of 2 unidentified products. The $\mathrm{Cu}-\mathrm{ZSM}-5$ catalyst produced only trace amounts of cyclohexanone, identified by retention time but too small for quantification. Zeolites ferrierite and $\beta$ produced very small amounts of unidentified products, lower than the limits of detection on the GCMS. No verifiable identities of these materials were found either through software library searches or with retention time and fragmentation pattern matching of standards. In this family of catalysts, the only material demonstrating quantifiable activity was the $\mathrm{Y}$ zeolite. In this case, the amount of product - cyclohexanol and cyclohexanone - was found to be stoichiometric based on the amount of peroxide added. Reaction blanks showed that the zeolite catalyst was required for this reaction to occur; the peroxide alone under the same conditions produced no products. This result, combined with the inactivity of the blanks, indicates that this particular catalyst is effective in activating peroxide, but not in maintaining a catalytic cycle in the present of air. Copper is known as the active metal in several peroxidase enzymes, but the lack of true catalysis in this case is surprising. The most plausible explanation for this chemistry is that this material is activating peroxide via oxygen atom transfer, accounting for the 1:1 molar quantities of product produced. Spectroscopic examination (FTIR using ATR and DRIFT attachments) before and after the reaction did not reveal any changes of note in any of the catalysts. Peaks attributed to the adsorption of products (predominately cyclohexanone) were observed, indicating that product retention in the catalyst was occurring.

For the $\mathrm{Cu} / \mathrm{Fe}$ mixed metal catalysts, materials that produced products in the oxidation of cyclohexane oxidation were the silica gel, ZSM-5, Y, mordenite, and ferrierite. In the case of the silica and the ZSM-5 materials, retention times identified the products as the expected cyclohexanol and cyclohexanone, but the quantities produced were lower than the quantitation limit based on the calibration curves generated for the GC-FID. The two additional peaks found from the mordenite oxidation also could not be identified or quantified using the GCMS software library. While in the case of the copper catalysts, only one material had sufficient activity to be quantified, in the case of the copper/iron mixed metal catalysts, three materials ( $\mathrm{Y}$, mordenite, and ferrierite) produced quantifiable and stoichiometric results based on peroxide. Most likely, these materials are also catalyzing oxygen atom transfer chemistry in this reaction as shown in Scheme 2 below. Enhancement of the activity is due to the presence of iron acting as a co-factor, similar to its behavior
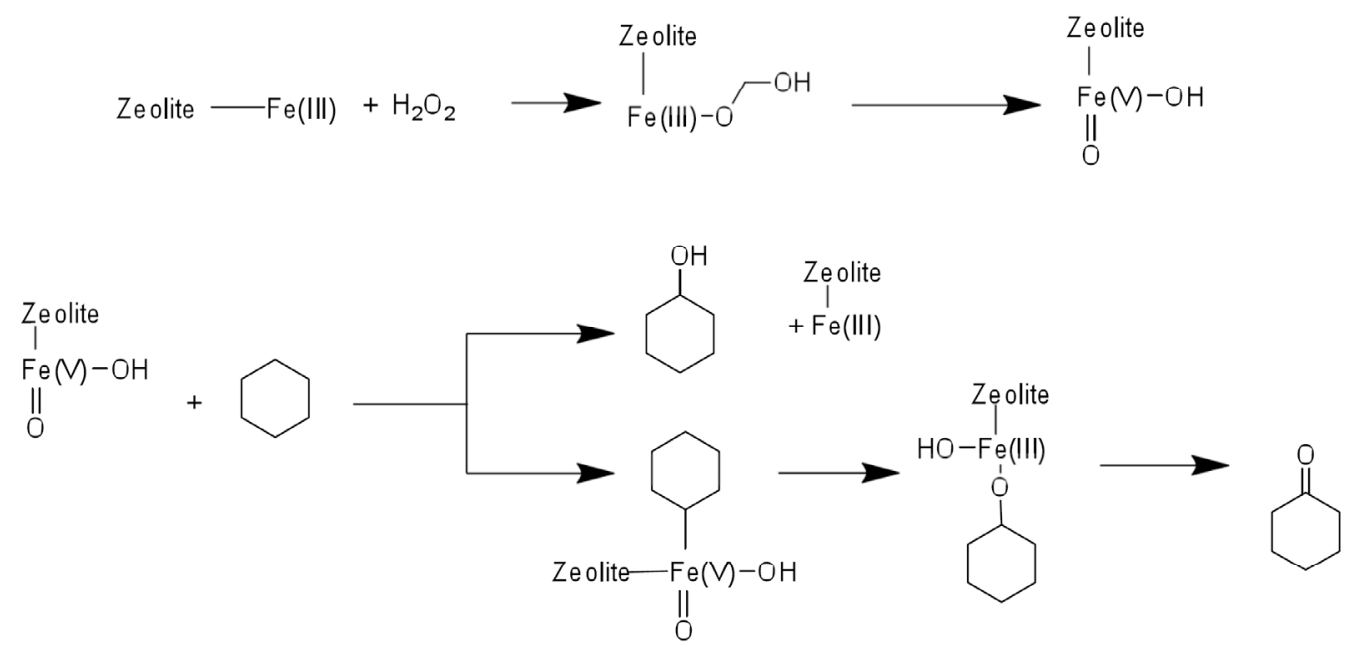

Scheme 2. Iron and Iron/Copper Catalyzed Reaction Pathways. 


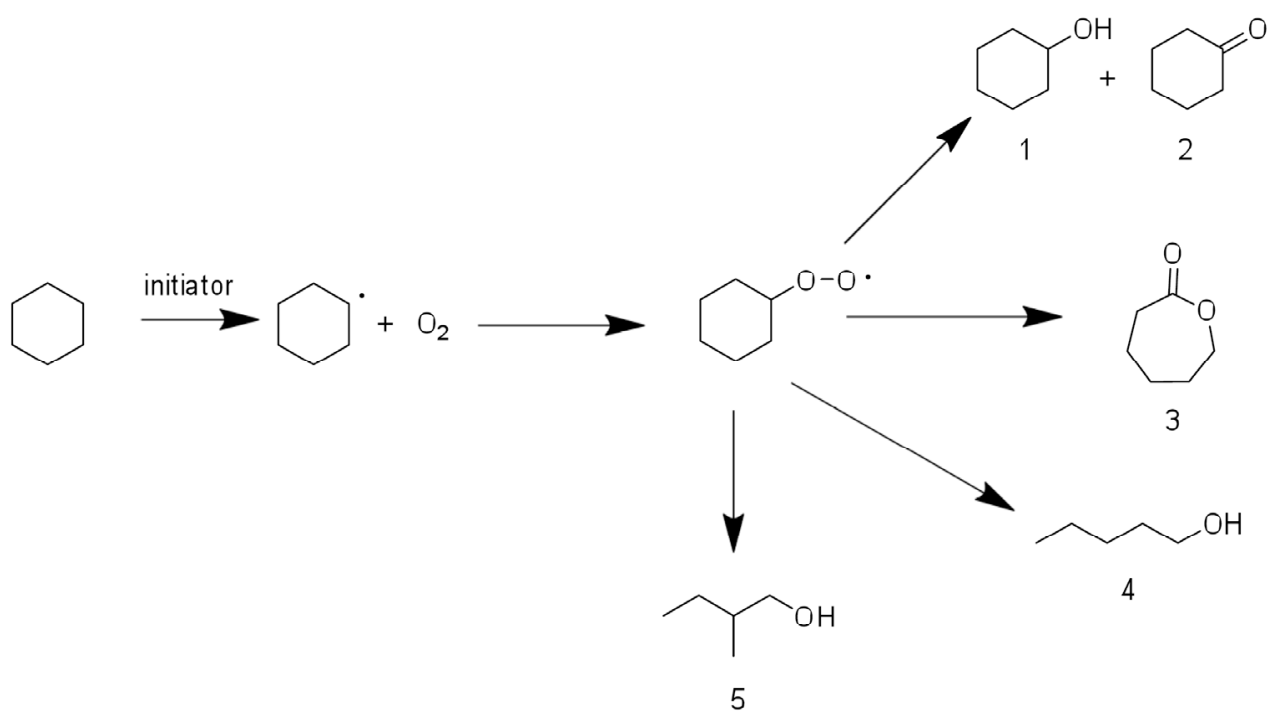

Scheme 3. Cobalt-zeolite catalyzed reaction pathways.
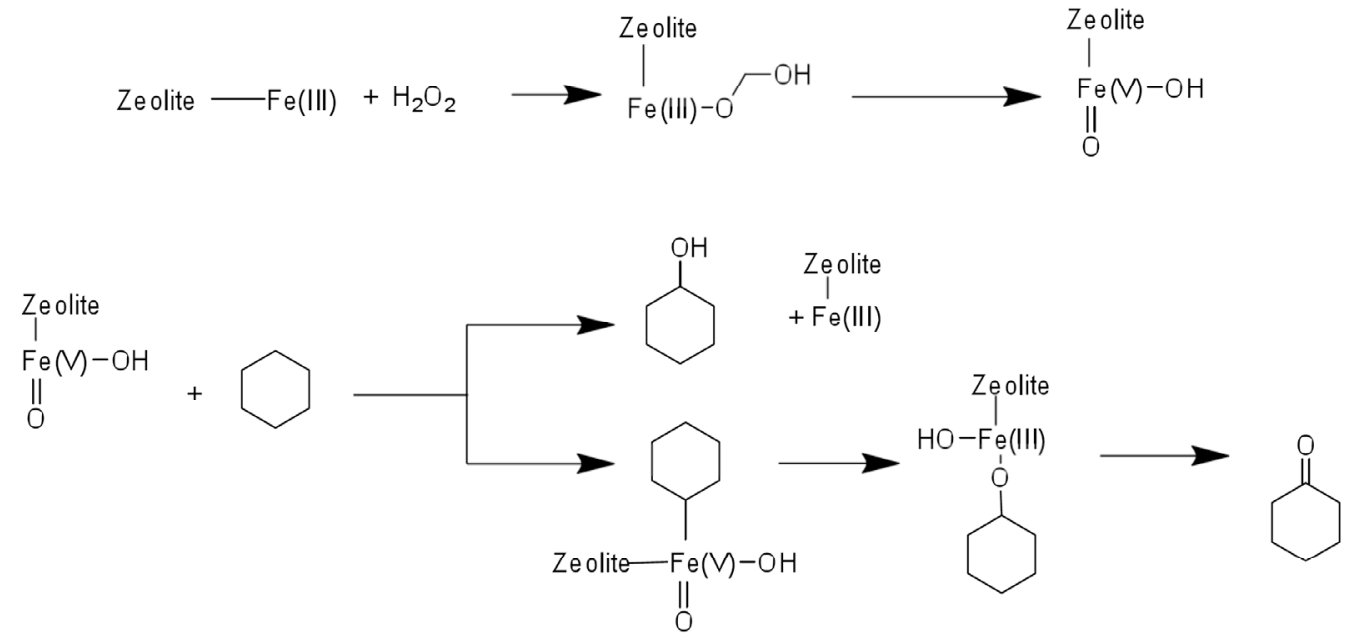

Scheme 4. Iron and iron/copper catalyzed reaction pathways.

in many copper-based enzymes. Further work to elucidate the mechanism as free radical or oxygen atom transfer chemistry is underway for the cobalt, copper and the mixed copper/iron catalysts.

The only catalyst that demonstrated any spectroscopic changes before and after the cyclohexane oxidations was the $\mathrm{Cu} / \mathrm{Fe}$ ferrierite material (Fig. 1), where the near IR region clearly shows an additional peak at $800 \mathrm{~cm}^{-1}$ and a slight downfield shift of the band just below $1100 \mathrm{~cm}^{-1}$. This shift is common to $\mathrm{SiO}_{2}$ bound materials, and may be due to changes in the zeolite support itself. No products, cyclohexanone or cyclohexanol, were found bound to the used catalyst using FTIR, so these peaks are not due to the presence of product adsorbed onto the catalyst. The changes are attributed to subtle changes in the catalyst over the course of the reaction; however, SEM analyses also showed no significant morphological changes in the ferrierite catalyst before and after the oxidation.

\section{CONCLUSIONS}

The oxidation of cyclohexane under very mild temperature and pressure conditions is possible using simply prepared transition metal oxides supported on zeolites. The cobalt materials produced a surprising range of products from the expected cyclohexanol and cyclohexanone, to the exciting production of 1-hexanol. The cobalt-based materials were the only materials tested that demonstrated true catalytic activity; all other active materials tested were stoichiometric based on the amount of peroxide added. The products of cyclohexanol and cyclohexanone were expected for a free radical based oxidation, the mechanism most likely involved in the cobalt mediated reactions. The stoichiometric ratio of products to peroxide indicates peroxide activation and selective oxygen atom transfer chemistry by the iron and iron/copper catalysts. Future work to investigate the potential of a one-step cyclohexane oxidation, as well as verification of the mechanisms involved in all three active systems is planned.

\section{ACKNOWLEDGEMENTS}

This work was supported financially through grants from the Georgia Southern University Faculty Research Committee and the Allen E. Paulsen College of Science and Technology Council of Undergraduate Research, the Georgia Southern University Honors Program, and the Georgia Southern University Department of Chemistry. The work of 


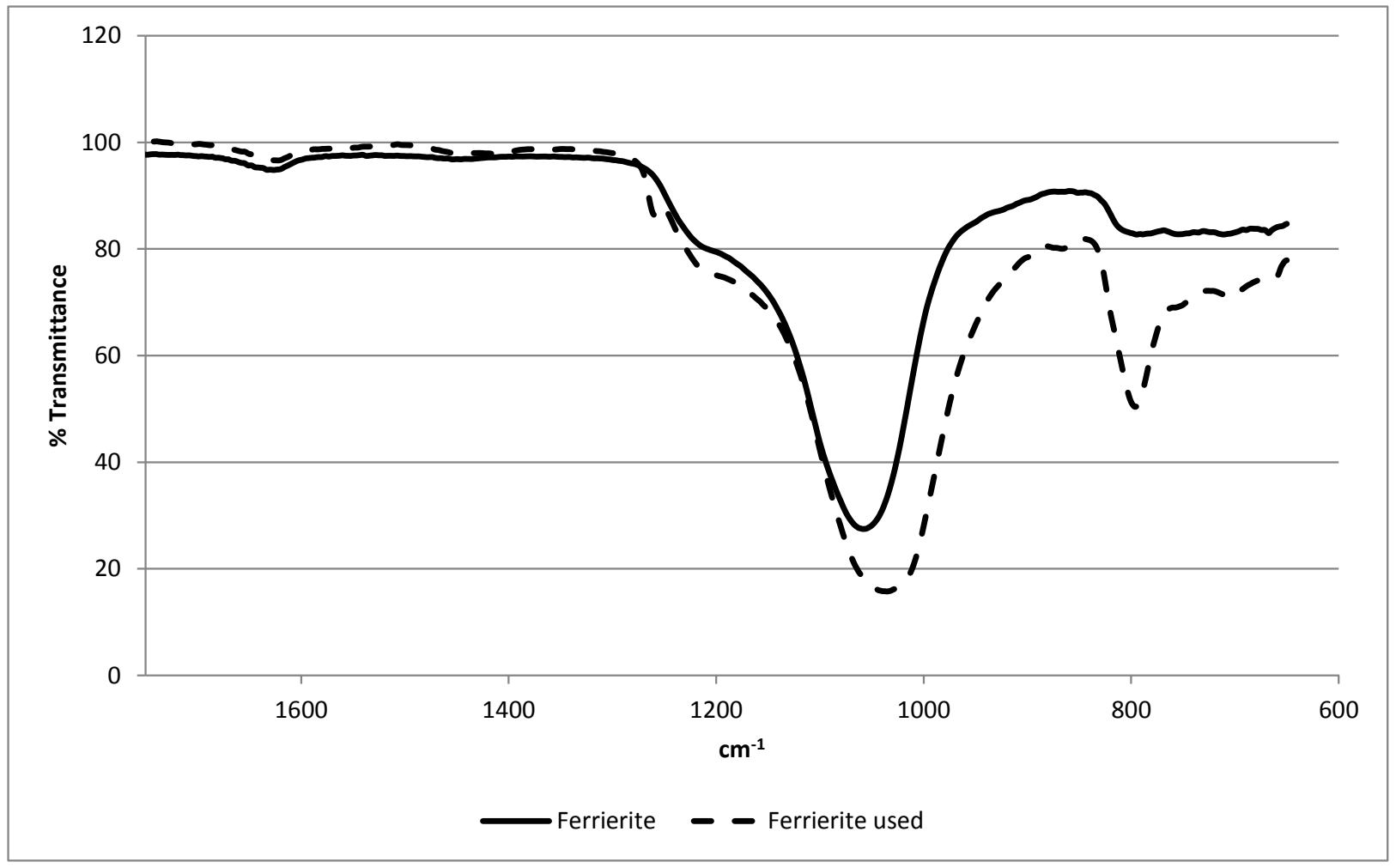

Fig. (1). FTIR spectra of $\mathrm{Cu} / \mathrm{Fe}$-Ferrierite catalysts before and after oxidation.

Mrs. Lori Ables of Ascend Performance Materials, LLC, (Pensacola, Florida) is gratefully acknowledged for the SEM analyses. The supporting efforts of Davis Research Group members Benjamin T. Manard and Brianna C. Hughes for their analytical methods development, and Brittany $\mathrm{M}$. Porter for her initial work on the manganese catalyst, are also acknowledged.

\section{CONFLICT OF INTEREST}

Declared none.

\section{REFERENCES}

[1] New Process Chemistry Roadmap. Available from: $\mathrm{http}: / /$ www.chemicalvision2020. org/pdfs/new chemistry_roadmap.pdf (accessed June 1, 2011).

[2] Chemicals Industry Catalysis Workshop Report. Available from: http://www.ccrhq. org/Vision2020/Catalysis (accessed June 1, 2011).

[3] Schuchardt, U.; Cardoso, D.; Sercheli, R.; Pereira, R.; da Cruz, R.; Guerreiro, M.; Mandelli, D.; Spinacé, E.; Pires, E. Cyclohexane oxidation continues to be a challenge. Appl. Catal., A 2001, 211(1), 117.

[4] Punniyamurthy, T.; Velusamy, S.; Iqbal, J. Recent advances in transition metal catalyzed oxidation of organic substrates with molecular oxygen. Chem. Rev., 2005, 105(6), 2329-2364.

[5] Salavati-Niasari, M.; Salimi, Z.; Bazarganipour, M.; Davar, F. Synthesis, characterization and catalytic oxidation of cyclohexane using a novel host (zeolite-Y)/guest (binuclear transition metal complexes) nanocomposite materials. Inorg. Chim. Acta., 2009, 362(10), 37153724.
[6] Salavati-Niasari, M.; Shakouri-Arani, M.; Davar, F. Flexible ligand synthesis, characterization and catalytic oxidation of cyclohexane with host (nanocavity of zeolite-Y)/guest (Mn (II), Co (II), Ni (II) and $\mathrm{Cu}$ (II) complexes of tetrahydro-salophen) nanocomposite materials. Microporous Mesoporous Mater., 2008, 116(1-3), 77-85.

[7] Salavati-Niasari, M.; Shaterian, M. Host (nanocavity of zeolite-Y)/guest (Mn (II), Co (II), Ni (II) and Cu (II) complexes of pentadendate Schiffbase ligand) nanocomposite materials (HGNM): application in the heterogeneous oxidation of cyclohexene. J. Porous Mater., 2008, 15(5), 581-588.

[8] Salavati-Niasari, M.; Sobhani, A. Ship-in-a-bottle synthesis, characterization and catalytic oxidation of cyclohexane by Host (nanopores of zeolite-Y)/guest (Mn (II), Co (II), $\mathrm{Ni}$ (II) and $\mathrm{Cu}$ (II) complexes of bis (salicyaldehyde) oxaloyldihydrazone) nanocomposite materials. J. Mol. Catal. A: Chem., 2008, 285(1-2), 58-67.

[9] Costa, A.; Ghesti, G.; de Macedo, J.; Braga, V.; Santos, M.; Dias, J.; Dias, S.. Immobilization of $\mathrm{Fe}, \mathrm{Mn}$ and $\mathrm{Co}$ tetraphenylporphyrin complexes in MCM-41 and their catalytic activity in cyclohexene oxidation reaction by hydrogen peroxide. J. Mol. Catal. A: Chem., 2008, 282(1-2), 149-157.

[10] Lee, S.; Oh, J.; Park, Y. Degradation of Phenol with Fenton-like Treatment by Using Heterogeneous Catalyst (Modified Iron Oxide) and Hydrogen Peroxide. Bull. Korean Chem. Soc., 2006, 27(4), 489-494.

[11] Lambert, A.; Macquarrie, D.; Carr, G.; Clark, J. The catalytic oxidation of cyclohexanone to caprolactone using hexagonal mesoporous silica supported $\mathrm{SbF}_{3}$. New J. Chem., 2000, 24(7), 485-488.

[12] Ten Brink, G.; Arends, I.; Sheldon, R.. The Baeyer- Villiger Reaction: New Developments toward Greener Procedures. Chem. Rev., 2004, 104(9), 4105-4124. 